\title{
Business model innovation for value and technology based preventive health care
}

\author{
Thomas Linner Dr.-Ing. ${ }^{a, *}$
}

Gabriela Solcanu MSc ${ }^{a}$

Camilla van den Boom MSc ${ }^{b}$

Hans Lingegard BSC ${ }^{C}$

Tifanny Istamto MSc MBA ${ }^{d}$

Gavin Proctor BA ${ }^{d}$

Yuan Lu PhD

Jim Steebakkers MSc ${ }^{\mathrm{e}}$

\begin{abstract}
${ }^{a}$ Chair of Building Realization and Robotics, Technische Universität München, Munich, Ger-

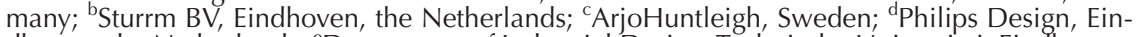
dhoven, the Netherlands; ' Department of Industrial Design, Technische Universiteit Eindhoven, Eindhoven, the Netherlands; *Corresponding author: thomas.linner@bri.arch.tu-muenchen.de
\end{abstract}

\begin{abstract}
T. Linner, G. Solcanu, C. van den Boom, H. Lingegard, T. Istamto, G. Proctor, Y. Lu, J. Steebakkers. Business model innovation for value and technology based preventive health care. Gerontechnology 2017;16(3):200-206; https://doi.org/10.4017/gt.2017.16.3.010.00 In this paper, a structured approach for the development of an initial business strategy blueprint for a complicated, multi-partner, multidisciplinary, early-stage research project focusing on value-based and preventive health care technology, is presented. Based on an in-depth analysis of the changes, trends, and innovation mechanisms in the health care industry and of the health care markets and reimbursement systems in the four use case countries, an initial context-specific and country adaptable business strategy was developed. In that context, a variety of tools (business model canvas, business model templates, platform thinking, etc.) were used to create a modular and adaptable business strategy that could be cost-efficient. Finally, it was analyzed to what extent a transformation of the project's partner current business models and roles, would be required. One of the biggest challenges in that context is to bridge the gap between the current business models of the individual partners and the novel strategies required to make REACH and its touchpoints (=smart products and services acting as data gathering devices) a real innovation.
\end{abstract}

Keywords: preventive health care technology, business model, innovation, value-based health care

This paper adopts a structured approach for the development of an initial business strategy blue print for a complicated, multi-partner, multidisciplinary, and early-stage research project focusing on value-based, preventive health care technology. By combining experiences and expertise from different types of stakeholders, a more holistic and realistic approach is taken to identify first steps in identifying realistic and financial viable business models in different markets.

The key aim of REACH is to contribute to the mitigation (for governments, payers, professional care providers and many other stakeholders) of the challenges imposed by aging societies and rising health care cost, and to find technical solutions and business models which are profitable and add values through its core idea by reducing the risk of functional loss or impairment of elderly citizens $(65+)$ by sensor-based monitoring and the promotion of physical activity.

In contrast to the currently predominating model of volume-based care, a care system focused the general measures to cure diseases or to slow down the course of illness, the REACH business model development aims to identify and test strategies that allow to monetize solution for elderly, patient engagement- and empowerment, and to sustain a longer period of healthy living 
through patient monitoring, activation, education, self-quantification and motivational methods in improving health behaviors.

The method for developing a business model following these premises also considers the specifics of the four REACH use case countries (Germany, Switzerland, the Netherlands, and Denmark) and the use case settings (Schön Klinik, ZuidZorg, Geneva Hospital, and Lyngby-Taerbeken Kommune). The methodology was based on a systematic 7-steps process (Figure 1). The first step was the identification of business model relevant trends and changes within the health care industry. The second step consisted of a preliminary analysis of the care market in EU and specifically in the four use case countries, considering such aspects as demographics, health in the old age, healthcare system, long-term care system, and reimbursement mechanisms. Steps 3-5 were performed during a Market Strategy Workshop in Eindhoven, the Netherlands.

As the first step, all of the relevant stakeholders of REACH per market were identified and mapped, as well as placed in a certain category. Secondly, considering the stakeholders, a value proposition was identified and the next bold steps of achieving the REACH acceptance of the society and deployment were discussed, along with the possible challenges and supporting matters. Next, a business model canvas was filled in by multidisciplinary experts and a general presentation of the business vision and strategy was analyzed and discussed per country. Finally, (step 6), a modular and generalized REACH business strategy was formulated based on the outcomes of the previous steps, where it was analyzed (step 7). In this step, an estimation was made on the needed transformation of the project's partner current business models. One of the biggest challenges in that context was to bridge the gap between the current business models of the individual partners and the novel strategies required to make $\mathrm{REACH}$ and its touchpoints (= smart products and services acting as data gathering devices) a real innovation.
For step 5, the business model canvas ${ }^{1}$ was used as the 'framework method'. It systematically combined other views and tools such as business model templates, for example, platform thinking ${ }^{2,3}$, and elements from the field of mass customization and personalization ${ }^{4}$ and as key element of $\mathrm{REACH}$ a freemium approach was suggested ${ }^{5}$.

\section{Changes, trends, AND INNOVATION MECHANisms IN THE HEALTH CARE INDUSTRY}

In this chapter, the changes, trends, and innovation mechanisms are identified and reviewed to develop a business model for value and technology-based preventive health care.

\section{The global trend: world population ageing and rising health care cost}

Between 2015 and 2030, the number of people in the world aged 60 years and over is projected to grow by $56 \%$, from 901 million to 1.4 billion, and by 2050 the global population of older persons is projected to more than double its size in 2015, reaching nearly 2.1 billion $^{6}$. At the same time, the continuous increase of health care expenditures, is a worldwide phenomenon in incumbent industrial nations such as Germany, Japan, US, Canada, etc. as well as in growing economies such as Korea and China. With regard to Europe, for example, the Directorate General for Economic and Financial Affairs notes that "[p]ublic provision of long-term care (LTC) will pose an increasing challenge to the sustainability of public finances in the EU, due to an ageing population" ${ }^{\prime 7}$. For instance, according to a baseline projection reported by Lipszyc et. al. ${ }^{7}$ the public expenditure on LTC in EU27 is expected to rise from 1.84\% of GDP in 2010 to $3.6 \%$ of GDP in 2060. However, the baseline projections are potentially underestimating the real increase in LTC public expenditure. Given the expected shortage of family caregivers in many countries, the increasing demand for LTC personnel, as well as the rising standards of life and the demand for higher quality services, the baseline projections are potentially underestimating the real increase

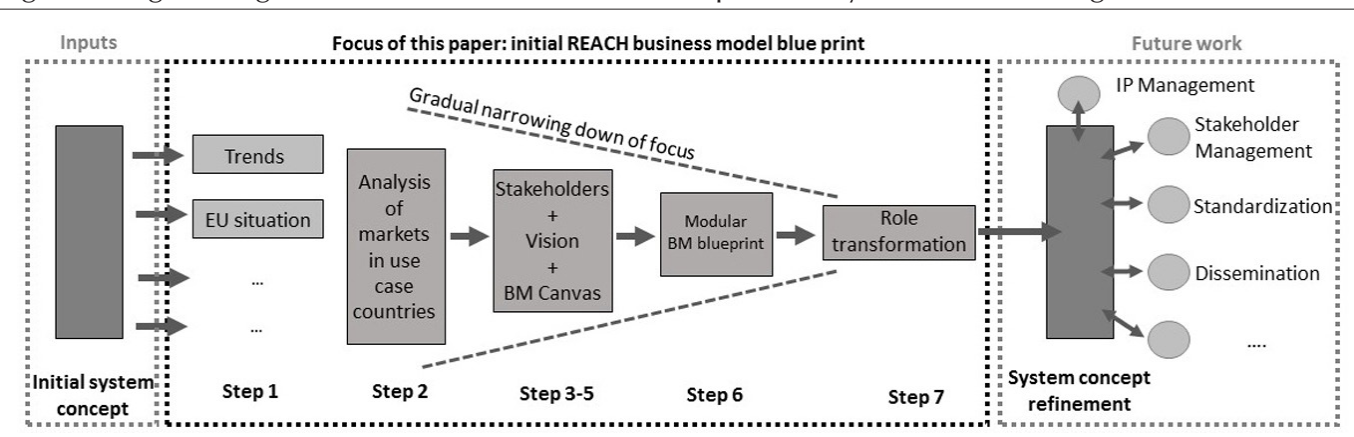

Figure 1. Use of a structured approach for the development of an initial business strategy blue print for a complex, multi-partner, multidisciplinary, early-stage research project focusing on value-based, preventive health care 
in LTC public expenditure, which could even triple by $2050^{8}$.

\section{Business model relevant trends and changes within the health care industry}

Besides the above mentioned global trend of population aging, a variety of further trends and changes are about to transform health care and ways of doing business. Some of these trends (e.g. value-based health care, preventive approaches) are indeed intensified by the aging population and the cost pressure imposed on health systems. The following aspects were some of the main reasons to transforming business model:

(i)From volume-based to value-based health care: With the change from volume-based care to value-based care, the cost structure changes as well ${ }^{9}$, i.e. the provision of solutions in general will become more expensive up front (e.g. for providers or individual payers), but due to better personalization and the inclusion of preventive measures, the overall cost will be saved in the long run (e.g. annually for the whole population). Furthermore, the change from the current 'feefor-service model' or 'diagnosis-related-group' to a 'value-based' or 'outcome-based' will considerably change the cost structure and architecture of business models ${ }^{10,11}$.

(ii)From therapy to early intervention and prevention: Early intervention and prevention approaches are relevant for population health management on one hand, but will also be heavily assessed in the next decade due to the cost pressure imposed on health systems by aging society and due to the rising health awareness of individuals, in particular in the highly industrialized nations. REACH will find ways to tackle these issues.

(iii)Digitalization and the rise of multisided platforms: A growing group of researchers ${ }^{2,3,11}$ is concerned with the analysis and the development of platform-based business models and multi-sided platforms. The success and rapid growth of multinational companies such as Apple, Uber, Airbnb, Facebook, and Amazon, is based on platform business models which have radically transformed their own industries and have obtained considerable marked shares. Choudary, Van Alstyne, \& Parker $^{1}$ argue that health care industry may be one of the next industries that will be transformed by platformbased business models.

(iv)Towards total products and integrated delivery systems: In order to be more competitive and to respond better to the trend towards more outcome-based health care, it is necessary for players in the health care industry to shift their focus from products to more integrated servic$\mathrm{es}^{13}$ and product-services bundles. Service models follow their own business model, science, and engineering rules $^{14-16}$ such as directly con-

necting the providers with the end-users which require collaborations with more players and to have their delivery facilitated by the Information and Communication Technology (ICT). This leads inevitably to multidisciplinary cooperation (such as REACH) that allows seamless integration and stimulates cost efficient delivery of complex product-service-systems. REACH represents an example of value chain that is able to deliver integrated product-service systems.

(v)From local to global: Traditionally, health care network is locally based ${ }^{10}$. However, due to the rising technology complexity and types of approaches used to provide value-based care, health care delivery and approaches need to be developed on an international scale and then adapted and customized to individual regions. $\mathrm{REACH}$ has partners that can drive international development and distribution from a central level (e.g. Philips, ArjoHuntleigh), and partners that are interested in the local adaptation of the REACH system (e.g. the four use case settings).

$\mathrm{REACH}$ is situated in this environment of changes and needs to utilize and capture values through the outlined changes. New technologies such as wearables and ambient sensors (key elements of REACH) which allow a real time monitoring and detailed insight into subtle health changes (and thus health outcomes), can measure health outcomes and will pave the way to a more value-based, preventive health care with outcomeoriented reimbursement models.

ANALYsis OF the heALTH AND CARE MARKET IN EUROPE AND THE FOUR REACH USE CASE COUNTRIES In this chapter the outcome of an in-depth analysis of the health care markets (trends, statistics, reimbursement systems, etc.) is briefly and exemplarily outlined. The full length, detailed analyses served as input for the next step (business model development). Following the preliminary analysis for the care markets in the four use case countries (Figure 2), a comparison between the four local situations was conducted. Part of the analysis was the identification of commonalities and differences of the healthcare markets of the four use case countries with regard to (1) demographics, (2) health in older age, (3) health care systems, (4) long-term care systems, (5) stakeholders, and (6) unique value propositions. Table 1 outlines the outcome of the comparative analysis of the (3) health care systems.

\section{Development of a modular business Strategy DRAFT FOR REACH}

Based on carefully aggregated market data and analyses, and together with the in parallel developed Touchpoints and Engine concept, a modular business strategy draft for REACH was developed. The draft considers the commonalities and 


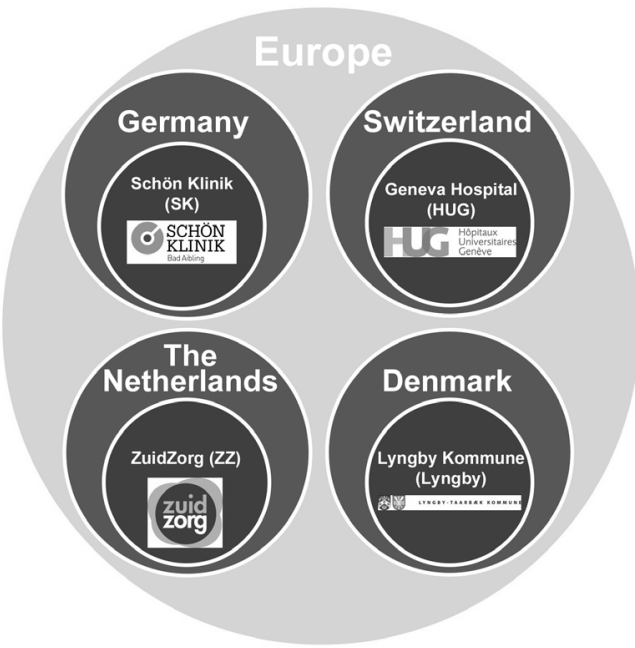

Figure 2. In-depth analysis of the four health care markets in which the four use case settings are situated

differences of the health care systems in the four countries, and the business models are based on the four use case settings. In this Chapter, the outcome of the business model development for the Netherlands can be exemplarily presented as the generalized and overall business model platform.

\section{The Market Strategy Workshop}

The Market Strategy Workshop was organized in order to assess the local market situation in the four use case countries and the way that the REACH system shall create, deliver, and capture value in respective countries. Due to different rules and regulations, reimbursement systems, and market potentials, the REACH concept shall be adapted to the country-specific context. A common business model platform functions as a basis and shall be the same for all four countries, but the particular business models might differ, due to country-specific factors. Based on the information regarding the EU and local care markets, a team composed of representatives of various REACH consortium members analyzed and synthesized the given information and discussed methods to implement $\mathrm{REACH}$ in the four different countries. They split into four teams to develop an initial market strategy on how REACH shall, at this stage, create, deliver, and capture value in each country. The teams thoroughly followed the aforementioned methodology and delivered an initial business model vision per each country, which was collectively discussed afterwards.

\section{Development of use case country specific busi- ness models: example of the Netherlands}

REACH has to find transparent and valid mechanisms to demonstrate its social and economic value (e.g. economic value of the disability-adjusted life years, spared though REACH), and/or address customer segments which have not yet been considered ('the black hole'), in order to gain credibility and funding in the Netherlands. A peculiarity of the Dutch social services, the benefits under both the LTC Act and the Social Support Act, offer a greater spectre of customer segments and opportunities/needs to fulfil, as well as the presence of several private health

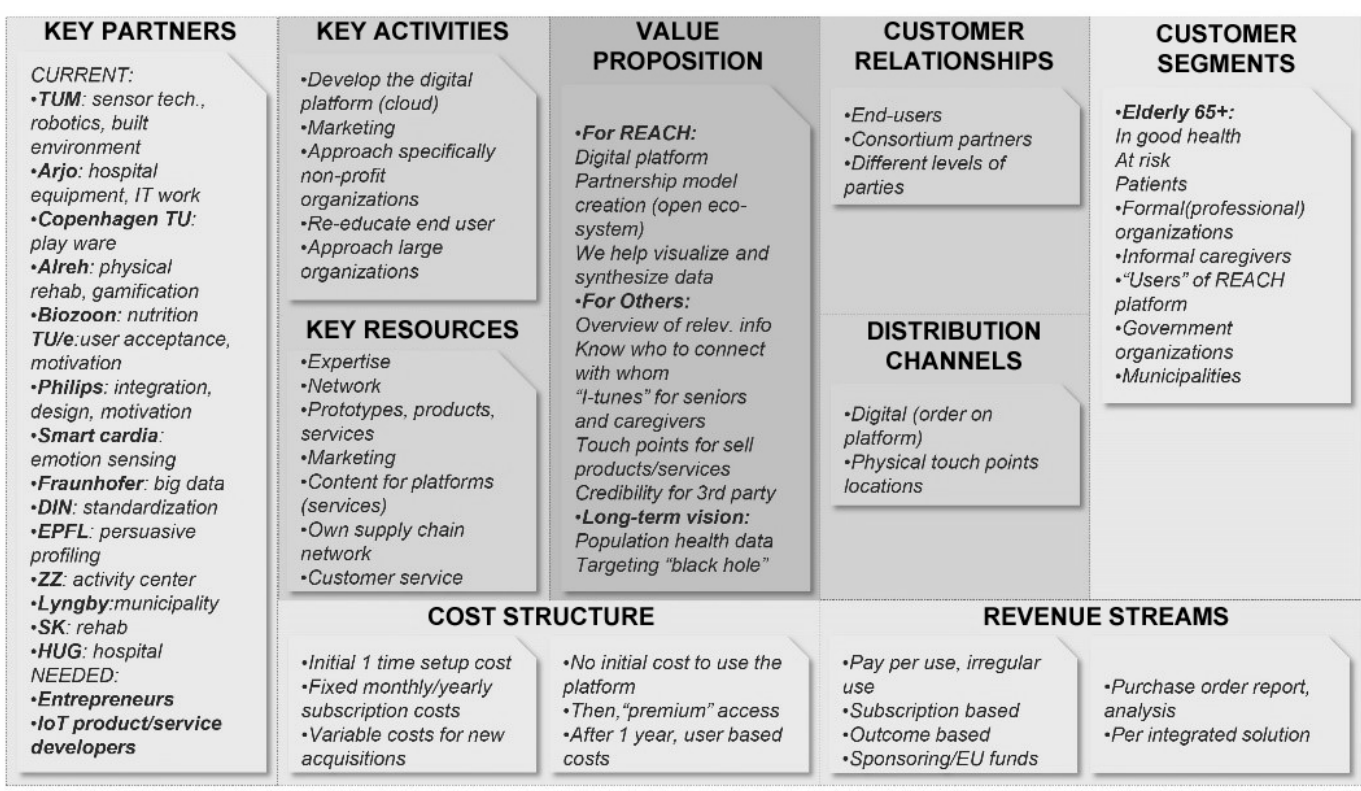

Figure 3. The REACH business model canvas applied to the context of the Netherlands established during the workshop 


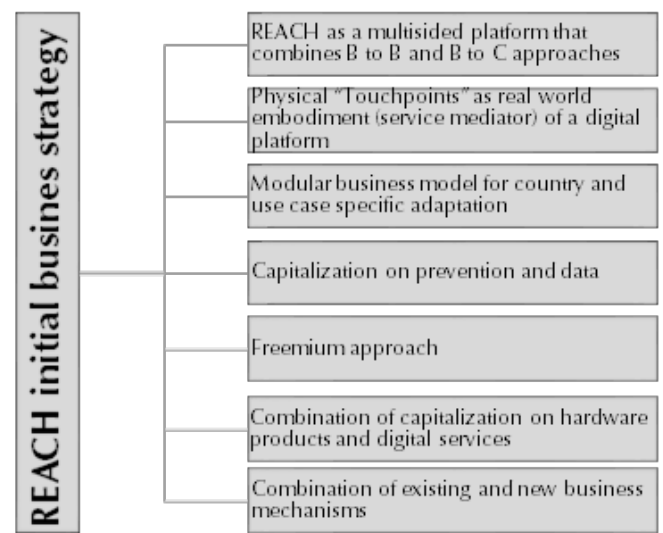

Figure 4. Generalized, overall REACH business model platform

insurers on market offer various possibilities of funding. Figure 3 outlines the REACH business model canvas applied to the context of the Netherlands established during the workshop.
Generalization: REACH initial business strategy

Based on the analyses conducted as part of the presented work, an initial draft for a modular business approach (co-adapted to a modular system architecture, the 'Touchpoints and Engine' concept) was developed to allow REACH fulfill the requirements of various countries and use case settings. First steps for monetizing value-based, personalized, and preventive care, and the large-scale utilization of data and a platform approach, were explored. Figure 4 summarizes the developed key aspects (building blocks) of the REACH initial business strategy which forms an overall REACH business model platform kit.

\section{TRANSFORMATION OF ROLES AND BUSINESS MODEL STRATEGIES OF THE REACH PARTNERS IN LIGHT OF THE PROPOSED VALUE PROPOSITIONS}

Based on the previous outlined analyses and the developed initial business model blueprint, the existing roles and business strategies for the value proposition is analyzed in table 2 .

Table 1. Exemplary outline of the outcome of the comparative analysis of the market situation in the use case countries for the factor 'health care systems'

\begin{tabular}{|c|c|}
\hline & \\
\hline GER & SWITZERLAND \\
\hline h care & $\begin{array}{l}\text { reg- } \\
\text { lefits } \\
\text { lan- }\end{array}$ \\
\hline $\begin{array}{l}\text { es of health insur- } \\
\text { "Public Health Insur- } \\
\text { nd "Private Health In- } \\
\text { ". }\end{array}$ & $\begin{array}{l}\text { datory health insurance } \\
(\mathrm{MHI}) \text {, which is purchased } \\
\text { by residents via premiums, } \\
\text { and covers } \mathrm{GP}^{\prime} \text { s and other } \\
\text { specialists' services. }\end{array}$ \\
\hline ublic health & $\begin{array}{l}\text { However, the insured per- } \\
\text { son pays part of the treat- } \\
\text { ment costs, through an an- }\end{array}$ \\
\hline
\end{tabular}
ployer and employee.

It is allowed for compulsory insurance companies to offer individual add-on benefits.
The compulsory insurance can be supplemented by private "complementary" insurance, which covers some additional treatment categories.

Cantons are responsible for securing health care provision for their populations, as well as are in charge of issuing and implementing health-related legislation, and they carry out preventive and health promotion activities.

NETHERLANDS

The Dutch health care system is governed by four basic healthcare-related acts: the Health Insurance Act (provides for hospital care), the Long-Term Care Act (focuses on other types of care), the Social Support Act and the Youth Act (the two prove for other forms of care and support).

According to the Health Insurance Act, all residents of the Netherlands shall possess a comprehensive basic health insurance package that covers all primary and curative care, offered by private, competitive health insurers.

The private mandatory health insurance package is $50 \%$ financed from payroll taxes paid by employers to a fund controlled by the Health regulator; the government contributes an additional $5 \%$; the remaining $45 \%$ is collected as premiums paid by the insured.

In Denmark, the health insurance system is public, in Germany partly public, while in Switzerland and the Netherlands the health insurance system is private.

In Denmark, the mandatory health insurance (MHI) package is covered by taxes, while in Germany, Switzerland and the Netherlands the $\mathrm{MHI}$ is partly or entirely covered by premiums paid by either the insured and/or their employer. 
Table 2. Transformation of roles and business model strategies of the REACH partners considering the proposed value proposition

REACH partner

\section{Current business strat-} egy

Future business strategy
Expected role in context of the development of the REACH touchpoint/engine concept

Technische Universi- R\&D in the developtät München (TUM) ment of ambient sensors

Develop and supply ambient sensors that are integrated into the individual touchpoints and connectable to the REACH engine

Testing and evaluation, Develop and supply intervention and motivaR\&D in motivational tion strategies; develop and supply engine

Danmarks Tekniske R\&D in motivational

Universitet (DTU) strategies and gamification

connectable touchpoints in the context of gaming and training;

Technische R\&D in motivational

Universiteit

Eindhoven (Tu/E) strategies and gamification

École Polytechnique

Fédérale de Lausanne Data science and R\&D (EPFL) $\begin{array}{ll}\begin{array}{l}\text { Copenhagen Univer- } \\ \text { sity }(\mathrm{CU})\end{array} & \begin{array}{l}\text { Research in community } \\ \text { health }\end{array}\end{array}$

Fraunhofer (Fraunho- Data analytics research fer) and consulting

\section{Development and supply of motivational} strategies.

\section{Develop and supply algorithms for health}

data analysis and recommender systems for the REACH engine/platform.

Develop and supply method to evaluate health outcomes in real time and utilize data, security and data privacy regimes.

Develop and supply algorithms for health data analysis and recommender systems for the REACH engine/platform.

Development of supply Make devices smart and turn them into data

Alreh Medical (AM) of transfer, mobility, and mobilization devices.

Biozoon (Biozoon) $\begin{aligned} & \text { Customized nutrition } \\ & \text { products }\end{aligned}$
vices; make devices engine/platform ready. Establish links to platforms/engines and provide beyond its food products services and total systems (including sensors, algorithms, etc.) relevant in the context of nutritional monitoring and intervention.

$\begin{array}{ll}\text { SmartCardia (SC) } & \begin{array}{l}\text { Medical-grade CE-certi- } \\ \text { fied wearable sensors }\end{array}\end{array}$
fied wearable sensors

Volume-based development, manufacturing ArjoHuntleigh $(\mathrm{AH})$ and sales of equipment and devices for rehabilitation and hospitals.

\section{Smart consumer inte-} grated solution with foPhilips (Philips) cus on different health phases: prevention, diagnosis, treatment, home care, etc.

\begin{tabular}{ll}
\hline $\begin{array}{l}\text { Deutsches Institut für } \\
\text { Normung (DIN) }\end{array}$ & Standardization \\
\hline Sturrm (Sturrm) & $\begin{array}{l}\text { Business model devel- } \\
\text { opment }\end{array}$ \\
\hline Zuidzorg (ZZ) & $\begin{array}{l}\text { Activity centers for el- } \\
\text { derly }\end{array}$
\end{tabular}
Lyngby-Taarbæk
Kommune (Lngby)

\section{Schön Kliniken (SK) Rehabilitation}

Hôpitaux

Universitaires de Care

Genève (HUG)

Health Insurance

Financing care and Rehabilitation treatments

Use of therapies, care

Elderly and rehabilitation if necessary
Medical-grade CE-certified wearable sensors and platform + superior analytics/algorithms Connection of services to their products for better personalization and value-based care. Extend functionality of their equipment/devices and connect services to their products though cooperation with other REACH partners, link their equipment/devices to engine platform for data utilization. Extend focus to home and remote care.

Extend the ecosystem \& solution around its digital health platform and switch gradually to a more platform based business model related to value-based healthcare

Standardization of processes and methods for value-based personalized health care

Platform based business model development and capitalization on data

High-tech activity centers, extended services and customer experience that foster healthy living and prevention

Provision of smart homes that foster healthy living and prevention based rehabilitation and remote monitoring

Extended services for personalized and valuebased tele-care

Financing of extended services for personal-

ized and value-based tele-care, rehabilitation Financier

and remote monitoring

Active participation to prevent diseases and stay healthy
Extended services for personalized and value-
Cross sectional contributor

Leader of the touchpoint cluster 'Gaming and Training'

Leader of the touchpoint cluster 'Socializing \& Nutritional Monitoring + Intervention'

key contributor to $\mathrm{REACH}$ Engine development

Contributor to the touchpoint cluster 'Gaming and Training'

Key contributor to REACH

Engine development

Leader of the touchpoint cluster 'Personal Mobility Device'

Leading contributor to the touchpoint cluster 'Socializing \& Nutritional Monitoring + Intervention'

Leader of the touchpoint cluster 'Wearables'

Leader of the touchpoint cluster 'Active Environment'

Contributor with regard to the cross-disciplinary integration of both touchpoints and engine functionality

Facilitate standardization and interoperability

Leader of business model development/ innovation

Care/intervention provider, use case setting

Care/intervention provider, use case setting

Care/intervention provider, use case setting

\section{Care/intervention provider,} use case setting and facilitator 


\section{Conclusion}

Following a clearly structured approach, an initial business strategy blueprint for a complex, multidisciplinary, early-stage research project focusing on value-based, preventive health care technology, was developed. First, the outcome of a thorough analysis of the changes, trends, and innovation mechanisms in the health care industry was presented. Then the general European health and care market was analyzed, creating a deeper understanding of the health and care markets in the four use case countries. Based on these analysis outcomes, an initial contextspecific business strategy was developed using a variety of tools (business model canvas, business model templates, platform thinking, etc.) and discussed during a market strategy development dedicated workshop. Finally, a modular and generalized REACH business strategy was formulated based on the outcomes of the previous steps, and it was analyzed to what extent a transformation of the project's partner current business models is required. The initial strategy draft presented in this paper will be further detailed, in particular by using the four use case settings (Schön Klinik, ZuidZorg, Geneva Hospital, and Lyngby-Taerbeken Kommune) as concrete examples towards a full business model. In this paper, the relevant elements in different markets were identified and will enable the generation of a more concrete value proposition with country specific healthcare elements that will fit into the introduced modular business model approach. Furthermore, the strategy will be set by steps aligned with other relevant and in parallel executed work such as the development of REACH system architecture, and detailed strategies for IP management, stakeholder management, standardization, and dissemination.

\section{Acknowledgements}

This project (and related work) presented in this paper has received funding from the European Union's Horizon 2020 research and innovation programme under grant agreement No 690425. The authors thank all partners of the REACH consortium for their contributions to the presented work.

\section{References}

1. Osterwalder A, Pigneur Y, Smith A. Business Model Generation. New York: John Wiley \& Sons 2013

2. Choudary SP, Van Alstyne MV, Parker GG. Platform revolution: How networked markets are transforming the economy and how to make them work for you. New York: W.W. Norton \& Company 2016

3. Evans DS, Schmalensee R. Matchmakers: The New Economics of Multisided Platforms. Boston MA: Harvard Business Review Press 2016

4. Piller FT. Handbook of research in mass customization and personalization. Singapore: World scientific 2010

5. Gassmann O, Frankenberger K, Csik M. The Business Model Navigator: 55 Models That Will Revolutionise Your Business. UK: Pearson education limited 2014

6. WHO. World report on ageing and health. Geneva: World Health Organization 2015

7. Lipszyc B, Sail E, Xavier A. Long-term care: need, use and expenditure in the EU-27. European Co-

mission 2012; https://doi.org/10.2765/27485

8. Colombo F, Llena-Nozal A, Mercier J, Tjadens F. Help Wanted? Providing and Paying for LongTerm Care. Paris: OECD Publishing 2011

9. Kaiser LS, Lee TH. Turning Value-Based Health Care into a Real Business Model 2015; https:// hbr.org/2015/10/turning-value-based-health-careinto-a-real-business-model; retrieved April 4, 2017

10. O'Riordan A, Elton J. Healthcare disrupted: Next generation business models and strategies. New York: John Wiley \& Sons 2016

11. Sharan AD, Schroeder GD, West ME, Vaccaro AR. (2016). Understanding Business Models in Health Care. Clinical Spine Surgery 2016; 29(4):158-160; https://doi.org/10.1097/BSD.0000000000000380

12. Tiwana A. Platform ecosystems: aligning architecture, governance, and strategy. Waltham MA: Morgan Kaufmann 2013

13. Pfannstiel MA, Rasche C. Service Business Model Innovation in Healthcare and Hospital Management: Models, Strategies, Tools. Switzerland: Springer 2016; https://doi.org/10.1007/978-3-319-46412-1

14. Curedale R. Service Design: 250 essential methods. Topanga CA: Design Community College Inc 2013

15. Maglio PP, Kieliszewski CA, Spohrer JC. Handbook of service science. New York: Springer 2010

16. Sakao T. Introduction to Product/Service-System Design. London: Springer 2009; https://doi. org/10.1007/978-1-84882-909-1 